\title{
Special Issue: Supporting Health and Psychosocial Well-Being for Refugees and Asylum Seekers
}

\author{
Mansha Parven Mirza \\ Department of Occupational Therapy, College of Applied Health Sciences, University of Illinois at Chicago, \\ 1919 W. Taylor Street, Chicago, IL 60612, USA; mmirza2@uic.edu
}

Received: 2 July 2019; Accepted: 2 July 2019; Published: 6 July 2019

With nearly 69 million people forcibly displaced from their homes, the global refugee situation has reached crisis proportions [1]. A record number of refugees and asylum seekers are fleeing their countries of origin in search of safety and resettlement. Faced with this influx, host countries are struggling to accommodate refugee migrants amid political opposition and limited material and human resources. As we approach the 70th anniversary of the 1951 UN Convention, and as political instability and civil unrest become more widespread and protracted, there is a growing push for humanitarian interventions to move beyond crisis response and toward long-term well-being of displaced populations. This special issue brings together seven articles that address health and psychosocial needs of displaced populations in different contexts and through the lens of disciplines as diverse as law, applied language studies, social work, psychology, occupational therapy, and international and public affairs.

Three of the articles in this issue are tied by the theme of transit. These articles explore the psychosocial needs of displaced individuals in the context of transit-living in transit in refugee camps, transiting between asylum-seeker and asylee status, and negotiating transit between 'illegal' and legal refugee status. In "The Highest Attainable Standard': The Right to Health for Refugees with Disabilities" [2], Smith-Khan and Crock discuss access to health and social services for individuals with disabilities living in refugee camps and settlements. Using the international human rights framework, specifically the UN Convention on the Rights of Persons with Disabilities, the authors argue for more disability-inclusiveness within humanitarian responses. Their arguments are particularly potent as they are grounded in evidence garnered from field research in six countries hosting some of the world's largest refugee populations.

Sivunen's "An Ethnographic Study of Deaf Refugees Seeking Asylum in Finland" [3] is another article that focuses on a marginalized and often neglected group among displaced populations. Using linguistic ethnographic methods, Sivunen explores how deaf asylum seekers navigate asylum procedures whilst living in reception centers in Finland. She highlights her research participants' communication difficulties, social isolation, and the violation of their legal right to a fair asylum procedure in the absence of regular access to interpreting services in their preferred sign language. This article is notable for underscoring the importance of civil society, specifically deaf Finnish volunteers who can serve as advocates, peer mentors, and role models for deaf asylum seekers. It is also unique in its application of innovative communication strategies to transcend multiple spoken and sign languages during the research process.

The third article that addresses the theme of transit is Alemi, Montgomery, and Stempel's "A Qualitative Study Exploring the Psychosocial Needs of Male Undocumented Afghan Migrants in Istanbul, Turkey" [4]. The article presents narratives informed by qualitative interviews with 15 Afghan asylum seekers living in Turkey. These narratives reveal how an ostensibly strong group of young able-bodied males is placed at high risk of exploitation and trauma on account of their risky journey from Afghanistan and their precarious living conditions in Turkey thereafter. While travelling 
from Afghanistan to Turkey, the young migrants were at the mercy of smugglers and subjected to financial exploitation, and in some cases, physical abuse. Once in Turkey, their struggles continued largely due to lack of legal refugee status under Turkish asylum and settlement laws. Consequently, they had no right to work nor access to medical care and found themselves relegated to the margins of society. Through these poignant narratives, the authors make the case that Afghan asylum seekers in Turkey are at risk of mental trauma and distress. They conclude their article with a call for culturally sensitive psychosocial supports that focus on building resilience among Afghan migrants in Turkey and on harnessing the social capital of the local Afghan community.

The next set of three articles address psychosocial interventions, both grassroots endeavors and those developed by advocates for refugees in resettlement countries. The first of these articles is Smith's "Traditional Dance as a Vehicle for Identity Construction and Social Engagement after Forced Migration" [5]. The article reports the findings of iterative, qualitative interviews with two Karen adults and eight Karen youth displaced from their native Myanmar and resettled in an urban area of the United States. The youth, who were born in refugee camps in Thailand and who represent the largest non-Burmese ethnic community in Myanmar, were deeply engaged in a traditional dance group. Smith posits that participating in their traditional dance offered opportunities for Karen youth to engage socially with others from their ethnic and cultural background. Surviving the Burmese government's onslaught on their land and way of life, and subsequently resettling in the United States, challenged their sense of identity and belonging. Traditional dance performances thus became a means to reaffirm their Karen identity and facilitated their adaptation to U.S. society.

In a similar vein, Zoellner and colleagues" article titled "Islamic Trauma Healing: Initial Feasibility and Pilot Data" [6], describes an innovative, trauma-focused intervention for Somali refugee adults resettled in the United States. Islamic Trauma Healing is a small-group intervention with two unique features-it is led by lay facilitators in local mosques and combines cognitive and exposure principles with Islamic spiritual beliefs and practices. The authors report the feasibility and acceptability of implementing the intervention with seven women and six men. Mixed methods were used to evaluate the program, including focus groups with participants and lay leaders, and pilot data on pre to post-intervention changes in trauma symptoms and well-being. The authors conclude that the program holds promise and serves as an exemplar of culturally tailored trauma-focused interventions for Muslim refugees. However, they also acknowledge limitations of their small-scale study and caution that full-scale clinical trials are needed to investigate the program's efficacy.

The third intervention-related article focuses on a pioneering program for resettled refugees with disabilities titled Partners of Refugees in Illinois Disability Employment (PRIDE) [7]. In "Fostering Community-Academic Partnerships to Promote Employment Opportunities for Refugees with Disabilities: Accomplishments, Dilemmas, and Deliberations", Mirza, Hasnain, and Duke describe and reflect on the developmental phase of this innovative program, and challenges encountered during its launch and implementation. The authors make a compelling case for economic participation as a means of social integration for disabled refugees resettled in the United States. They argue that refugees with disabilities are deprived of economic opportunities owing to language barriers, ableist hiring policies, and limited awareness of disability-related supports and resources among refugee service providers. Based in the Midwestern United States, PRIDE uses interdisciplinary approaches to promote employment and self-sufficiency among refugees with disabilities through trainings, job supports, and capacity building. This article effectively captures steps taken to build trust and engage local refugee communities and refugee service providers for successful program implementation and sustainability.

With the final article, "Engaging Organizations of Persons with Disabilities in Humanitarian Response" [8] this issue comes full circle. Where the first article by Smith-Khan and Crock sheds light on the exclusion of persons with disabilities within humanitarian programs, the final article by Buscher highlights efforts to rectify this situation. Buscher reports on the work of the Women's Refugee Commission (WRC) a non-governmental organization that focuses on displaced women, children, and youth. The article summarizes a decade's worth of activism by the WRC for disability inclusion in 
humanitarian responses, specifically in the areas of gender-based violence, child protection, and sexual and reproductive health. Particularly noteworthy are the WRC's efforts to engage local organizations of persons with disabilities (DPOs) in humanitarian programs. The article concludes on the optimistic note of DPOs being actively engaged in drafting of the groundbreaking U.N. Inter-Agency Standing Committee Guidelines on the Inclusion of Persons with Disabilities in Humanitarian Action.

Collectively, the seven articles in this issue offer several important insights. First, they demonstrate that the vulnerability and resilience of displaced individuals is context-specific. Those considered traditionally secure, such as young, able-bodied men can become disempowered and rendered vulnerable in a state of legal limbo and economic marginalization. Conversely, those considered traditionally vulnerable, such as refugees with disabilities, can be empowered with the right supports and legal protections. Second, interventions to address the health and psychosocial needs of displaced individuals are more likely to be effective if adapted and customized for specific groups. Finally, grassroots efforts and community collaborations are critical for effective and sustainable intervention programs. One limitation of this special issue is limited scholarly representation from the Global South. Approximately $80 \%$ of displaced people are hosted in developing countries in the Global South [1]. While three articles in this issue offer a glimpse into ground realities in refugee-hosting developing countries, the lack of local scholarship undermines the body of literature on this topic. We hope that this limitation is redressed in future issues and that this issue serves as the beginning of ongoing dialogue on health and psychosocial concerns among displaced populations.

Funding: The development of this article was not supported by any external funding.

Conflicts of Interest: The author declares no conflicts of interest.

\section{References}

1. UN High Commissioner for Refugees (UNHCR) Statistical Yearbook, Figures at a Glance. Available online: http://www.unhcr.org/en-us/figures-at-a-glance.html (accessed on 28 April 2019).

2. Smith-Khan, L.; Crock, M. 'The highest attainable standard': The right to health for refugees with disabilities. Societies 2019, 9, 33. [CrossRef]

3. Sivunen, N. An Ethnographic study of deaf refugees seeking asylum in Finland. Societies 2019, 9, 2. [CrossRef]

4. Alemi, Q.; Montgomery, S.; Stempel, C. A qualitative study exploring the psychosocial needs of male undocumented afghan migrants in Istanbul, Turkey. Societies 2018, 8, 22. [CrossRef]

5. Smith, Y. Traditional Dance as a vehicle for identity construction and social engagement after forced migration. Societies 2018, 8, 67. [CrossRef]

6. Zoellner, L.; Graham, B.; Marks, E.; Feeny, N.; Bentley, J.; Franklin, A.; Lang, D. Islamic trauma healing: initial feasibility and pilot data. Societies 2018, 8, 47. [CrossRef]

7. Mirza, M.; Hasnain, R.; Duke, K. Fostering community-academic partnerships to promote employment opportunities for refugees with disabilities: Accomplishments, dilemmas, and deliberations. Societies 2018, 8, 86. [CrossRef]

8. Buscher, D. Engaging organizations of persons with disabilities in humanitarian responses. Societies 2018, 8 , 107. [CrossRef]

(C) 2019 by the author. Licensee MDPI, Basel, Switzerland. This article is an open access article distributed under the terms and conditions of the Creative Commons Attribution (CC BY) license (http://creativecommons.org/licenses/by/4.0/). 